\title{
Patient satisfaction after switching from warfarin to apixaban in patients with nonvalvular atrial fibrillation:AGAIN study
}

This article was published in the following Dove Press journal:

Patient Preference and Adherence

\section{Yukihiro Koretsune \\ Takanori Ikeda ${ }^{2}$ \\ Ken Kozuma ${ }^{3}$ \\ Teruyuki Hirano 4 \\ Masahiro Yasaka ${ }^{5}$ \\ Makoto Kida ${ }^{6}$ \\ Motohiko Chachin ${ }^{7}$ \\ Miki Imura ${ }^{7}$}

'National Hospital Organization, Osaka National Hospital, Osaka,

${ }^{2}$ Department of Cardiovascular Medicine, Toho University Graduate School of Medicine, Toho University, Tokyo, ${ }^{3}$ Division of Cardiology, Teikyo University School of Medicine, Teikyo University, Tokyo, ${ }^{4}$ Department of Stroke and Cerebrovascular Medicine, Kyorin University, Tokyo, ${ }^{5}$ Department of Cerebrovascular Medicine and Neurology, National Hospital Organization, Kyushu Medical Center, Fukuoka, ${ }^{6}$ Medical \& Development, Bristol-Myers Squibb K.K., Tokyo, ${ }^{7}$ Pfizer Innovative Health Medical Affairs, Pfizer Japan Inc., Tokyo, Japan

Correspondence: Miki Imura Pfizer Innovative Health Medical Affairs, Pfizer Japan Inc., 3-22-7 Yoyogi, Shibuya-ku, Tokyo I5I 8589, Japan

Tel +818050013070

Fax +8I 353099198

Email miki.imura@pfizer.com
Purpose: Patients treated with warfarin must adhere to frequent monitoring, dietary restrictions, and complicated dose adjustments. Apixaban, a direct factor Xa inhibitor, is an alternative to warfarin that may reduce patient burdens associated with warfarin therapy. However, there is limited evidence pertaining to patient satisfaction with anticoagulant therapies in Japanese patients. The purpose of this observational study was to investigate changes in patient satisfaction after switching from warfarin to apixaban.

Patients and methods: Nonvalvular atrial fibrillation (NVAF) patients who were scheduled to switch anticoagulants from warfarin to apixaban were enrolled and treated with apixaban for 12 weeks. Patient satisfaction was assessed before the change in medication and after 12 weeks of treatment with apixaban using the Anti-Clot Treatment Scale (ACTS), a patient-reported instrument for measuring satisfaction with anticoagulation treatment. The ACTS includes a 12-item burden scale (maximum 60 points) and a 3-item benefit scale (maximum 15 points).

Results: Among 732 NVAF patients enrolled, the full analysis set consisted of 697 patients who completed two ACTS assessments (one before the medication change and one 12 weeks after the change). Mean ( \pm standard deviation) patient age was 76.2 \pm 9.1 years and mean $\mathrm{CHADS}_{2}$ score was 2.5 \pm 1.3 . There were no significant changes in ACTS benefit scores. However, ACTS burden scores showed significant improvements at Week 12 compared to baseline $(55.6 \pm 5.3$ at Week 12 and $49.7 \pm 8.7$ at baseline; $P<0.0001$ ). Factors associated with changes in ACTS burden scores from the multiple logistic regression analysis were age $\geq 70$ years (odds ratio [OR]: 1.86; 95\% confidence interval [CI]: 1.12-3.10; $P=0.0169)$, baseline ACTS burden score (OR: $0.79 ; 95 \% \mathrm{CI}: 0.75-0.82 ; P<0.0001$ ), and use of non-steroidal anti-inflammatory drugs/ antiplatelet drugs (OR: 0.60; 95\% CI: 0.36-1.00; $P=0.0499$ ).

Conclusion: Switching from warfarin to apixaban improved patient satisfaction with anticoagulant therapy in Japanese patients with NVAF by reducing burden of treatment.

Keywords: atrial fibrillation, apixaban, warfarin, patient satisfaction, Japanese patients

\section{Plain language summary}

For many years, warfarin has been the standard of care in oral anticoagulation for the prevention of ischemic stroke in patients with nonvalvular atrial fibrillation (NVAF). However, patients treated with warfarin must adhere to frequent monitoring, dietary restrictions, and complicated dose adjustments. We investigated changes in patient satisfaction after switching from warfarin to apixaban. The results showed that switching from warfarin to apixaban improved patient satisfaction with anticoagulant therapy in Japanese patients with NVAF by reducing burden of treatment and that apixaban may be a suitable alternative to warfarin to reduce patient burdens associated with warfarin therapy. 


\section{Introduction}

It is well known that atrial fibrillation (AF) is strongly associated with ischemic stroke. Furthermore, major cardiovascular risk factors including age, male gender, hypertension, elevated blood pressure, heart failure, and obesity are known to increase the risk of AF. ${ }^{1-3}$ Studies show that the prevalence of $\mathrm{AF}$ is increasing in the aging Japanese population. ${ }^{4-6}$ Warfarin has been widely used to prevent the occurrence of stroke as a complication of AF. However, warfarin can be difficult for patients to manage, as it requires regular monitoring of prothrombin time/international normalized ratio (PT-INR) and also as it interacts with many foods and medications. ${ }^{7}$ It has been also suggested that warfarin therapy may be associated with an increase in arterial stiffness. ${ }^{8-10}$ Therefore, development of direct oral anticoagulant (DOAC) drugs offers potential benefits for patients requiring anticoagulant therapy.

Apixaban is an oral direct factor Xa inhibitor with potent antithrombotic effects. The ARISTOTLE trial showed noninferiority and superiority of apixaban over warfarin in the primary efficacy endpoint (stroke or systemic embolism) and superiority in the primary safety endpoint (major bleeding) in patients with nonvalvular AF (NVAF). ${ }^{11}$ The 2013 Guidelines for Pharmacotherapy of Atrial Fibrillation issued by the Japanese Circulation Society recommend that "when both warfarin and DOACs are indicated, the use of DOACs is desirable". ${ }^{12}$ However, the 2014 guidelines from the American College of Cardiology, American Heart Association, and Heart Rhythm Society state that "if patients are stable, easily controlled, and satisfied with warfarin therapy, it is not necessary to change to one of the newer agents". The guidelines do, however, recommend discussing DOACs as an option for patients who are appropriate candidates. ${ }^{12}$ In this context, patient satisfaction becomes an important factor in selecting or changing anticoagulant therapy in patients with AF. Additionally, patient preference may have a large impact on long-term adherence to prescribed medications ${ }^{13,14}$ and, consequently, on clinical prognosis.

A previous study reported that $58 \%$ of patients, particularly those $>70$ years of age or male, hoped to switch from warfarin to a DOAC. ${ }^{15}$ Furthermore, Elewa et al ${ }^{16}$ reported that although patient satisfaction with warfarin therapy was adequate, many patients still hoped to switch to DOACs to reduce hospital visits and to avoid interactions with medications and diet. In addition, it was shown that the price of DOACs is a major barrier to switching to anticoagulants. ${ }^{7}$ Unfortunately, in Japan, there are scant data regarding patient satisfaction with prescribed anticoagulants among patients with NVAF in real-world clinical settings. Such data could help inform clinical decisions surrounding anticoagulant choice - specifically, whether switching from warfarin to a DOAC would be beneficial for patients. ${ }^{17}$ In this study, we investigated the levels of patient satisfaction according to the Anti-Clot Treatment Scale (ACTS) when warfarin was switched to apixaban in Japanese patients with NVAF.

\section{Patients and methods Study design}

This was a prospective, short-term, multicenter, single-arm, observational study designed to evaluate changes in patient satisfaction associated with switching from warfarin to apixaban. This study was conducted in compliance with all international and local rules including the Ethical Guidelines for Medical and Health Research Involving Human Subjects, the Declaration of Helsinki, and Japan's Act on the Protection of Personal Information. The study was approved by institutional ethics committees or the central ethical committee. Written informed consent was obtained from every patient. The study is registered with UMIN-CTR, a clinical trial registry in Japan (study ID: UMIN000018970).

\section{Study sites}

This study was conducted at a total of 149 institutions in Japan. Hospitals accounted for 58 of all the study sites and institutions specializing in cardiology accounted for 125 sites.

\section{Study population}

This was an observational study without interventions or force to change medications by physicians and, therefore, the study protocol did not determine the treatment prescribed by physicians. Only NVAF patients whose anticoagulant was being switched from warfarin to apixaban for reasons unrelated to this study, such as medically important reasons (strict adherence to treatment guidelines, labile PT-INR control, potential drug-drug interactions, etc) and patient request, were enrolled in this study. Patients were excluded for contraindications or off-label use of apixaban. The enrollment period was between September 2015 and October 2016.

\section{Outcomes}

The primary objective of this study was to evaluate the change in patient satisfaction after switching from warfarin to apixaban in real-world settings in Japan. The primary endpoint was the change in patient satisfaction from baseline to Week 12 after switching to apixaban to evaluate the 
short-term impact on patient satisfaction; this was assessed using the ACTS burden and benefit scales. ACTS is an instrument that evaluates patient-reported satisfaction with anticoagulation therapy. It includes the 12-item ACTS burden scale (maximum of 60 points) and the 3 -item ACTS benefit scale (maximum of 15 points). ${ }^{18}$ The former includes questions regarding limitations of daily activities due to bleeding concerns and inconvenience associated with anticoagulant therapy. The latter includes questions regarding satisfaction or reassurance of anticoagulant therapy (Table S1 for details). The secondary objective of this study was to identify the key factors for improvement in patient satisfaction when switching from warfarin to apixaban.

\section{Data collection}

At each site, data were collected from medical records by investigators and their clinical research coordinators and entered into Viedoc (Uppsala, Sweden), an electronic data capture (EDC) system developed by DOT WORLD Co., Ltd. (Tokyo, Japan). Patients answered the ACTS and study-specific questionnaire by themselves for baseline characteristics, which were then faxed to Mebix, Inc. (Tokyo, Japan), a contract research organization. Mebix then entered questionnaire data into the EDC system and ensured the accuracy and validity of the data. Source data verification was conducted randomly at $10 \%$ of the study sites to confirm consistency between the original medical records and data entered into the EDC. Based on patient background data, $\mathrm{CHADS}_{2}$ and $\mathrm{CHA}_{2} \mathrm{DS}_{2}-\mathrm{VASc}$ scores (scores to evaluate the risk of stroke) and HAS-BLED scores (score to evaluate the risk of bleeding) were calculated.

\section{Statistical methods}

We separately compared ACTS burden and benefit scores at baseline to scores reported 12 weeks after patients switched to apixaban using the paired $t$-test with a two-sided significance level of $5 \%$. In addition, the Wilcoxon rank sum test was conducted with a significance level of 0.05 (two-sided) to assess the robustness of the paired $t$-test. Descriptive statistics were used to describe demographics, clinical characteristics, and patient satisfaction from the ACTS.

To identify independent factors affecting patient satisfaction after switching to apixaban, we performed a multiple logistic regression analysis using the changes in each ACTS score (burden and benefit) as dichotomous variables: "improvers" (patients whose ACTS scores improved at Week 12) and "non-improvers" (those whose ACTS scores decreased or did not change at Week 12). Univariate logistic regression models were fitted for each variable and variables with $P$-values $<0.2$ were candidates for a subsequent stepwise selection procedure. Variables that were considered likely to show an association with each other were paired, and the relationship between the variables in each pair was investigated and reported as the Pearson productmoment correlation coefficient. If the correlation coefficient was $>0.9$, one of the variables was removed from the analysis to avoid multicollinearity. Gender, age (categorized into three age ranges: $<70,70-79$, and $\geq 80$ years), ACTS scores at baseline, history of bleeding, and history of stroke, as well as presence of concomitant diseases such as hypertension, diabetes, heart failure, and myocardial infarction, and use of concomitant medications (eg, non-steroidal anti-inflammatory drugs [NSAIDs] and/or antiplatelet drugs) were examined as covariates. The constructed model ("base model") included gender and factors with $P$-values $<0.2$ : age ( $\geq 70$ years), ACTS scores at baseline, history of stroke, and use of NSAIDs, and/or antiplatelet drugs. In Model 1 and Model 2, other variables to be examined were added to the base model. Factors with a $P$-value $<0.05$ were considered to be significantly associated with the outcomes.

\section{Results}

From September 2015 to October 2016, 732 patients with NVAF were enrolled in the study; of these, 697 patients met the criteria of having at least two ACTS assessments (one before and one after switching medications) for inclusion in the full analysis set.

\section{Patient characteristics}

Demographic and clinical characteristics of the patients are shown in Table 1. A majority of patients were $\geq 70$ years of age and were male. Creatinine clearance was $60.8 \pm 43.0$ (mean $\pm \mathrm{SD}$ ) $\mathrm{mL} / \mathrm{min}$, suggesting that many patients had slight renal impairment. Mean $\mathrm{CHADS}_{2}$ and $\mathrm{CHA}_{2} \mathrm{DS}_{2}-\mathrm{VASc}$ scores indicated that patients registered in the study had a relatively higher risk of stroke. INR at baseline was 2.0 \pm 0.6 , which is within the therapeutic range recommended in the treatment guidelines. A majority of patients did not earn income by working, and in more than half of the patients, the self-pay portion of total medical costs was $10 \%$.

\section{Patient satisfaction}

Figure 1 shows the changes in ACTS burden score and ACTS benefit score from baseline to Week 12 after switching to apixaban. The ACTS burden score significantly improved at Week 12 compared to baseline $(55.6 \pm 5.3$ vs $49.7 \pm 8.7$; 
Table I Patient characteristics in FAS

\begin{tabular}{|c|c|c|}
\hline Characteristics & $\mathbf{N}$ & $\begin{array}{l}\mathrm{n}(\%) \text { or } \\
\text { mean } \pm \text { SD }\end{array}$ \\
\hline Male & 697 & $433(62.1)$ \\
\hline Age (years) & 697 & $76.2 \pm 9.1$ \\
\hline Body weight $(\mathrm{kg})$ & 572 & $60.6 \pm 12.6$ \\
\hline Creatinine clearance $(\mathrm{mL} / \mathrm{min})$ & 331 & $60.8 \pm 43.0$ \\
\hline INR & 672 & $1.96 \pm 0.64$ \\
\hline FIR & 672 & $60.2 \pm 30.4$ \\
\hline $\mathrm{FIR} \geq 70 \%$ & 672 & $296(42.5)$ \\
\hline $\mathrm{FIR} \geq 60 \%$ & 672 & $373(53.5)$ \\
\hline $\mathrm{CHA}_{2} \mathrm{DS}_{2}-\mathrm{VASc}$ score & 697 & $4.0 \pm 1.7$ \\
\hline $\mathrm{CHADS}_{2}$ score & 697 & $2.5 \pm 1.3$ \\
\hline HAS-BLED score & 697 & $2.6 \pm 1.1$ \\
\hline Duration of $\mathrm{AF}$ (years) & 590 & $7.3 \pm 5.4$ \\
\hline Duration of warfarin therapy (years) & 587 & $6.1 \pm 4.2$ \\
\hline \multicolumn{3}{|l|}{ Concomitant medications } \\
\hline Use of antiplatelet drugs and/or NSAIDs & 697 & I $44(20.7)$ \\
\hline Total number of medications $\mathrm{s}^{\mathrm{a}}$ & 697 & $5.5 \pm 3.3$ \\
\hline \multicolumn{3}{|l|}{ Socioeconomic status } \\
\hline Income other than pension & 694 & $196(28.1)$ \\
\hline Self-pay portion of total medical costs & 697 & \\
\hline $0 \%$ & & $104(14.9)$ \\
\hline $10 \%$ & & $4 I I(59.0)$ \\
\hline $20 \%$ & & $42(6.0)$ \\
\hline $30 \%$ & & 139 (19.9) \\
\hline $100 \%$ & & I (0.I) \\
\hline $\begin{array}{l}\text { Patient understanding of anticoagulant therapy } \\
\text { Importance of treatment }\end{array}$ & 697 & \\
\hline Very high & & $242(34.7)$ \\
\hline High & & $422(60.5)$ \\
\hline Low & & $31(4.4)$ \\
\hline Very low & & $2(0.3)$ \\
\hline \multicolumn{3}{|l|}{ Risk of treatment } \\
\hline Very high & & 229 (32.9) \\
\hline High & & $424(60.8)$ \\
\hline Low & & $4 \mid(5.9)$ \\
\hline Very low & & $3(0.4)$ \\
\hline
\end{tabular}

Notes: ${ }^{a}$ Except warfarin or apixaban. The total number of patients in the FAS was 697. Data are shown as $n(\%)$ or mean \pm SD.

Abbreviations: AF, atrial fibrillation; FAS, full analysis set; FIR, frequency in range; INR, international normalized ratio; NSAID, nonsteroidal anti-inflammatory drug; SD, standard deviation.

$P<0.0001)$. However, there was no significant change in the ACTS benefit score (Week 12, 10.5 \pm 2.8 vs baseline, 10.4 $\pm 3.3 ; P=0.3129)$.

Among the components of the ACTS burden score, the question 5 Limit eat/drink showed the largest improvement (mean [range] score at baseline: 3.3 [3.2-3.4]; Week 12: 4.7 [4.7-4.8]). In contrast to the burden score, there was no component of the ACTS benefit score that changed substantially after switching to apixaban (Table S1). Table 2 shows the differences in patient demographic and clinical characteristics between patients whose ACTS burden score improved ("improvers") and those whose ACTS burden score did not improve ("non-improvers"). $\mathrm{CHA}_{2} \mathrm{DS}_{2}$-VASc and $\mathrm{CHADS}_{2}$

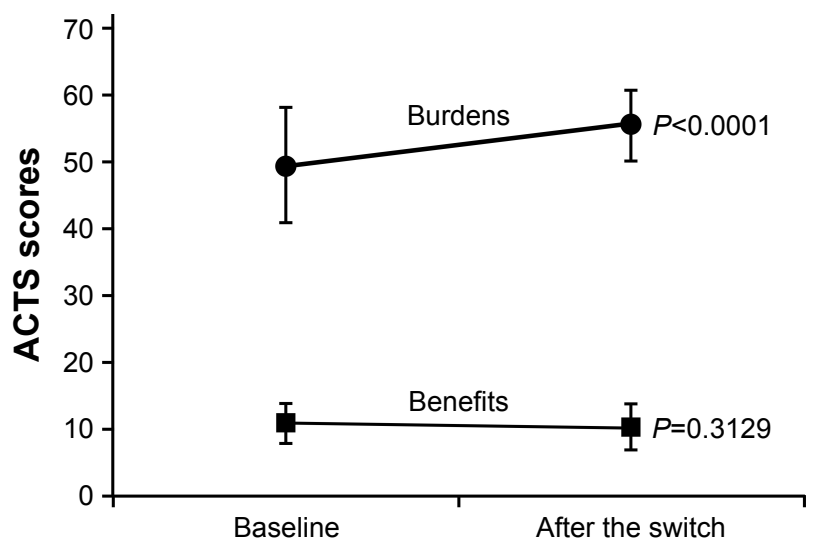

Figure I Changes in ACTS burden score and ACTS benefit score.

Notes: Changes from baseline are shown in ACTS burden and benefit scores at Week 12 after switching from warfarin to apixaban; values are mean $\pm S D$; $\mathrm{N}=697$ (FAS).

Abbreviations: ACTS, Anti-Clot Treatment Scale; FAS, full analysis set; SD, standard deviation.

scores were higher in improvers than in non-improvers. The percentage of patients with a history of stroke was significantly $(P<0.05)$ higher in the improver group. More patients in the improver group compared to the non-improver group had received apixaban $2.5 \mathrm{mg}$ twice daily (BID). The use of NSAIDs and/or antiplatelet drugs was also slightly lower in the improver group versus the non-improver group, although the difference was not statistically significant $(19.7 \%$ vs $23.6 \%, P=0.2836$ ). In addition, there were significant differences in the reasons for changing to apixaban from patients' perspectives (such as dietary restrictions and recommendations from persons other than physicians), as well as physicians' perspectives (including bleeding risk associated with warfarin; $P<0.05$ ). Table $\mathrm{S} 2$ provides detailed results of the background differences between ACTS benefit score in improvers and non-improvers.

\section{Multiple logistic regression analysis}

We conducted a multiple logistic regression analysis to investigate factors associated with changes in ACTS burden and benefit scores. As shown in "Patients and methods" section, we preliminarily built two logistic regression models and ultimately obtained the base model (Model 3) to identify factors that predicted improvement in ACTS burden score. The base model revealed that age, baseline ACTS score, history of stroke, and use of NSAIDs/antiplatelet drugs were significantly associated $(P<0.1)$ with improvement of the ACTS burden score (Table 3).

Other factors were added to the base model and multiple logistic regression analysis. We found that the following factors were not significant predictors for ACTS 
Table 2 Patient characteristics among ACTS burden "improvers" and "non-improvers"

\begin{tabular}{|c|c|c|c|c|}
\hline Characteristics & Whole FAS & Improvers & Non-improvers & $P$-value \\
\hline $\mathrm{N}(\%)$ & $697(100 \%)$ & $519(74.5 \%)$ & $178(25.5 \%)$ & \\
\hline Male & $433(62.1 \%)$ & $315(60.7 \%)$ & $118(66.3 \%)$ & 0.2100 \\
\hline Age (years) & $76.2 \pm 9.1$ & $76.2 \pm 9.3$ & $76.1 \pm 8.7$ & 0.7637 \\
\hline$<65$ & $71(10.2 \%)$ & $54(10.4 \%)$ & $17(9.6 \%)$ & 0.9140 \\
\hline $65-69$ & 80 (II.5\%) & $56(10.8 \%)$ & $24(13.5 \%)$ & \\
\hline $70-74$ & $107(15.4 \%)$ & $82(15.8 \%)$ & $25(14.0 \%)$ & \\
\hline $75-79$ & $160(23.0 \%)$ & $119(22.9 \%)$ & $41(23.0 \%)$ & \\
\hline $80-84$ & $157(22.5 \%)$ & 115 (22.2\%) & $42(23.6 \%)$ & \\
\hline$\geq 85$ & $122(17.5 \%)$ & $93(17.9 \%)$ & $29(16.3 \%)$ & \\
\hline Body weight (kg) & $60.6 \pm 12.6$ & $60.8 \pm 12.8$ & $60.2 \pm 12.1$ & 0.6178 \\
\hline Creatinine clearance $(\mathrm{mL} / \mathrm{min})$ & $60.8 \pm 43.0$ & $60.4 \pm 46.2$ & $62.5 \pm 26.9$ & 0.3724 \\
\hline FIR & $60.2 \pm 30.4$ & $60.1 \pm 30.4$ & $60.5 \pm 30.6$ & 0.9019 \\
\hline$<20 \%$ & $85(12.2 \%)$ & $61(11.8 \%)$ & $24(13.5 \%)$ & 0.1259 \\
\hline $20 \%-39 \%$ & $70(10.0 \%)$ & $60(11.6 \%)$ & $10(5.6 \%)$ & \\
\hline $40 \%-59 \%$ & $144(20.7 \%)$ & $102(19.7 \%)$ & $42(23.6 \%)$ & \\
\hline $60 \%-79 \%$ & I 46 (20.9\%) & 105 (20.2\%) & $4 \mathrm{I}(23.0 \%)$ & \\
\hline$\geq 80 \%$ & $227(32.6 \%)$ & $173(33.3 \%)$ & $54(30.3 \%)$ & \\
\hline Concomitant medications & $5.5 \pm 3.3$ & $5.5 \pm 3.2$ & $5.6 \pm 3.5$ & 0.9223 \\
\hline $0-2$ & $127(18.2 \%)$ & $89(17.1 \%)$ & $38(21.3 \%)$ & 0.2564 \\
\hline $3-4$ & $150(21.5 \%)$ & $117(22.5 \%)$ & $33(18.5 \%)$ & \\
\hline $5-6$ & $|7|(24.5 \%)$ & $135(26.0 \%)$ & $36(20.2 \%)$ & \\
\hline $7-8$ & $132(18.9 \%)$ & $94(18.1 \%)$ & $38(21.3 \%)$ & \\
\hline$\geq 9$ & $117(16.8 \%)$ & $84(16.2 \%)$ & $33(18.5 \%)$ & \\
\hline Duration of AF (years) & $7.3 \pm 5.4$ & $7.1 \pm 5.3$ & $7.6 \pm 5.6$ & 0.3613 \\
\hline Duration of warfarin therapy (years) & $6.1 \pm 4.2$ & $6.0 \pm 4.1$ & $6.4 \pm 4.5$ & 0.5214 \\
\hline $\mathrm{CHA}_{2} \mathrm{DS}_{2}$-VASc score & $4.0 \pm 1.7$ & $4.1 \pm 1.7$ & $3.8 \pm 1.6$ & 0.0276 \\
\hline$<2$ & $44(6.3 \%)$ & $32(6.2 \%)$ & $12(6.7 \%)$ & 0.3369 \\
\hline 2 & 87 (12.5\%) & $58(11.2 \%)$ & $29(16.3 \%)$ & \\
\hline 3 & $139(19.9 \%)$ & 101 (19.5\%) & $38(21.3 \%)$ & \\
\hline 4 & $172(24.7 \%)$ & 127 (24.5\%) & 45 (25.3\%) & \\
\hline 5 & $120(17.2 \%)$ & 94 (18.1\%) & 26 (14.6\%) & \\
\hline$\geq 6$ & 135 (19.4\%) & 107 (20.6\%) & $28(15.7 \%)$ & \\
\hline $\mathrm{CHADS}_{2}$ score & $2.5 \pm 1.3$ & $2.6 \pm 1.4$ & $2.3 \pm 1.3$ & 0.0126 \\
\hline$<2$ & $167(24.0 \%)$ & II 8 (22.7\%) & 49 (27.5\%) & 0.0106 \\
\hline 2 & $204(29.3 \%)$ & 140 (27.0\%) & $64(36.0 \%)$ & \\
\hline 3 & $168(24.1 \%)$ & $138(26.6 \%)$ & 30 (16.9\%) & \\
\hline$\geq 4$ & $158(22.7 \%)$ & $123(23.7 \%)$ & 35 (19.7\%) & \\
\hline HAS-BLED score & $2.6 \pm 1.1$ & $2.6 \pm 1.1$ & $2.5 \pm 1.1$ & 0.6027 \\
\hline$<1$ & 95 (I3.6\%) & $64(12.3 \%)$ & 31 (17.4\%) & 0.4895 \\
\hline 2 & $258(37.0 \%)$ & 198 (38.2\%) & $60(33.7 \%)$ & \\
\hline 3 & $212(30.4 \%)$ & $160(30.8 \%)$ & $52(29.2 \%)$ & \\
\hline 4 & 101 (14.5\%) & $74(14.3 \%)$ & 27 (I5.2\%) & \\
\hline$\geq 5$ & 31 (4.4\%) & 23 (4.4\%) & $8(4.5 \%)$ & \\
\hline \multicolumn{5}{|c|}{ Patient understanding of warfarin therapy } \\
\hline \multicolumn{5}{|l|}{ Importance of therapy } \\
\hline Very high & $242(34.7 \%)$ & $184(35.5 \%)$ & $58(32.6 \%)$ & 0.8339 \\
\hline High & $422(60.5 \%)$ & 309 (59.5\%) & $113(63.5 \%)$ & \\
\hline Low & $31(4.4 \%)$ & $24(4.6 \%)$ & $7(3.9 \%)$ & \\
\hline Very low & $2(0.3 \%)$ & $2(0.4 \%)$ & $0(0.0 \%)$ & \\
\hline \multicolumn{5}{|l|}{ Risk of therapy } \\
\hline Very high & $229(32.9 \%)$ & 175 (33.7\%) & $54(30.3 \%)$ & 0.4386 \\
\hline High & $424(60.8 \%)$ & $314(60.5 \%)$ & $110(61.8 \%)$ & \\
\hline Low & $4 \mid(5.9 \%)$ & $27(5.2 \%)$ & $14(7.9 \%)$ & \\
\hline Very low & $3(0.4 \%)$ & $3(0.6 \%)$ & $0(0.0 \%)$ & \\
\hline
\end{tabular}


Table 2 (Continued)

\begin{tabular}{|c|c|c|c|c|}
\hline Characteristics & Whole FAS & Improvers & Non-improvers & $P$-value \\
\hline \multicolumn{5}{|l|}{ Reasons for changing from warfarin to apixaban } \\
\hline \multicolumn{5}{|l|}{ Physician perspective } \\
\hline Unstable PT-INR & $258(37.0 \%)$ & $193(37.2 \%)$ & $65(36.5 \%)$ & 0.9284 \\
\hline Adverse event with warfarin & $43(6.2 \%)$ & $37(7.1 \%)$ & $6(3.4 \%)$ & 0.1022 \\
\hline Drug interaction with other medications & $49(7.0 \%)$ & 37 (7.1\%) & $12(6.7 \%)$ & 1.0000 \\
\hline Inconvenience of regular PT-INR monitoring & $28 \mathrm{I}(40.3 \%)$ & $202(38.9 \%)$ & 79 (44.4\%) & 0.2155 \\
\hline Concerns about high bleeding risk with warfarin & $176(25.3 \%)$ & $138(26.6 \%)$ & $38(21.3 \%)$ & 0.1936 \\
\hline Warfarin bleeding risk & 47 (6.7\%) & $4 \mathrm{I}(7.9 \%)$ & $6(3.4 \%)$ & 0.0379 \\
\hline At the timing of ablation & $7(1.0 \%)$ & $4(0.8 \%)$ & $3(1.7 \%)$ & 0.3797 \\
\hline Other medical reasons & $10(1.4 \%)$ & $7(1.3 \%)$ & $3(1.7 \%)$ & 0.7212 \\
\hline \multicolumn{5}{|l|}{ Patient perspective } \\
\hline Inconvenience of regular PT-INR monitoring & $136(19.5 \%)$ & $100(19.3 \%)$ & $36(20.2 \%)$ & 0.8266 \\
\hline Dietary restriction & $238(34.1 \%)$ & $191(36.8 \%)$ & 47 (26.4\%) & 0.0133 \\
\hline Concerns about high bleeding risk with warfarin & $21(3.0 \%)$ & $14(2.7 \%)$ & 7 (3.9\%) & 0.4462 \\
\hline Good reputation of apixaban & $122(17.5 \%)$ & $85(16.4 \%)$ & $37(20.8 \%)$ & 0.2083 \\
\hline Recommendation from family or acquaintance & $22(3.2 \%)$ & $10(1.9 \%)$ & $12(6.7 \%)$ & 0.0044 \\
\hline Others & $15(2.2 \%)$ & $10(1.9 \%)$ & $5(2.8 \%)$ & 0.5493 \\
\hline Income other than pension & $196(28.1 \%)$ & $143(27.6 \%)$ & $53(29.8 \%)$ & 0.4977 \\
\hline \multicolumn{5}{|l|}{ Self-pay portion of total medical costs } \\
\hline $0 \%$ & 104 (14.9\%) & 77 (14.8\%) & $27(\mid 5.2 \%)$ & 0.9731 \\
\hline $10 \%$ & $411(59.0 \%)$ & $304(58.6 \%)$ & $107(60.1 \%)$ & \\
\hline $20 \%$ & $42(6.0 \%)$ & $31(6.0 \%)$ & II (6.2\%) & \\
\hline $30 \%$ & 139 (19.9\%) & $106(20.4 \%)$ & $33(18.5 \%)$ & \\
\hline $100 \%$ & $\mathrm{I}(0.1 \%)$ & I $(0.2 \%)$ & $0(0.0 \%)$ & \\
\hline \multicolumn{5}{|l|}{ Dose of apixaban } \\
\hline $2.5 \mathrm{mg}$ BID & $328(47.1 \%)$ & $255(49.1 \%)$ & $73(41.0 \%)$ & 0.0499 \\
\hline 5 mg BID & $363(52.1 \%)$ & 258 (49.7\%) & $105(59.0 \%)$ & \\
\hline Other & $6(0.9 \%)$ & $6(1.2 \%)$ & $0(0.0 \%)$ & \\
\hline \multicolumn{5}{|l|}{ Concomitant diseases } \\
\hline Bleeding history & 75 (I0.8\%) & $59(11.4 \%)$ & $16(9.0 \%)$ & 0.4046 \\
\hline Hypertension & $550(78.9 \%)$ & $415(80.0 \%)$ & $135(75.8 \%)$ & 0.2436 \\
\hline Diabetes & $192(27.5 \%)$ & $142(27.4 \%)$ & $50(28.1 \%)$ & 0.8464 \\
\hline Heart failure & 276 (39.6\%) & 209 (40.3\%) & $67(37.6 \%)$ & 0.5942 \\
\hline Myocardial infarction ${ }^{\mathrm{a}}$ & $153(22.0 \%)$ & $112(21.6 \%)$ & $4 \mathrm{I}(23.0 \%)$ & 0.6761 \\
\hline Stroke ${ }^{b}$ & $150(21.5 \%)$ & $126(24.3 \%)$ & $24(13.5 \%)$ & 0.0021 \\
\hline Renal dysfunction & $20(2.9 \%)$ & $15(2.9 \%)$ & $5(2.8 \%)$ & 1.0000 \\
\hline Hepatic dysfunction & $25(3.6 \%)$ & $22(4.2 \%)$ & $3(1.7 \%)$ & 0.1595 \\
\hline Labile PT-INR & $245(35.2 \%)$ & $176(33.9 \%)$ & 69 (38.8\%) & 0.2750 \\
\hline Use of antiplatelet drugs and/or NSAIDs & 144 (20.7\%) & $102(19.7 \%)$ & $42(23.6 \%)$ & 0.2836 \\
\hline
\end{tabular}

Notes: ancludes myocardial infarction, periphery arteriosclerotic disease, and plaque. 'Includes stroke, transient ischemic attack, and embolism. Data are shown as $\mathrm{n}$ (\%) or mean \pm SD. "Improver" refers to patients whose ACTS burden score improved after switching to apixaban, while "non-improver" refers to patients whose burden score did not change or worsened after switching. P-values were calculated by using the Wilcoxon rank sum test or Fisher's exact test.

Abbreviations: ACTS, Anti-Clot Treatment Scale; AF, atrial fibrillation; BID, twice daily; FAS, full analysis set; FIR, frequency in range; NSAID, nonsteroidal anti-inflammatory drug; PT-INR, prothrombin time/international normalized ratio; SD, standard deviation.

burden improvement: frequency in range (FIR), $\mathrm{CHADS}_{2}$, $\mathrm{CHA}_{2} \mathrm{DS}_{2}-\mathrm{VASc}$, and HAS-BLED scores; patient's understanding of anticoagulant therapy; patient's perspective on switching to apixaban; socioeconomic factors (income from employment and self-pay ratio); and physician's perspective on switching to apixaban (Tables S3- $\underline{\mathrm{S} 5}$ ).

The multiple logistic regression analysis yielded several independent factors associated with improvement of ACTS benefit score after switching to apixaban: ACTS benefit score at baseline, age $\geq 70$ years, history of bleeding, history of acute myocardial infarction, use of NSAIDs/antiplatelet drugs, and use of apixaban $5 \mathrm{mg}$ daily (Table S6).

\section{Discussion}

In this study, we investigated changes in patient satisfaction, as measured by the ACTS score, in Japanese patients with NVAF who switched from warfarin to apixaban. To our knowledge, this is one of the few studies that demonstrates a significant improvement in patient satisfaction with anticoagulant therapy in patients with NVAF. Additionally, we 
Table 3 Logistic regression analysis to identify factors associated with improvement of ACTS burden scores

\begin{tabular}{|c|c|c|c|c|c|c|c|c|c|}
\hline \multirow[t]{2}{*}{ Characteristics } & \multicolumn{3}{|c|}{ Model I } & \multicolumn{3}{|c|}{ Model 2} & \multicolumn{3}{|c|}{ Model 3 (base model) } \\
\hline & OR & $95 \% \mathrm{Cl}$ & $P$-value & OR & $95 \% \mathrm{Cl}$ & $P$-value & OR & $95 \% \mathrm{Cl}$ & $P$-value \\
\hline Male & 0.85 & $0.55-1.30$ & 0.4457 & 0.87 & $0.56-1.34$ & 0.5284 & 0.90 & $0.58-1.38$ & 0.6273 \\
\hline Age $<70$ years & 1.00 & & & 1.00 & & & 1.00 & & \\
\hline Age $70-79$ years & 1.97 & $\mathrm{I} .14-3.4 \mathrm{I}$ & 0.0147 & 2.03 & $1.17-3.52$ & 0.0121 & 1.86 & $1.12-3.10$ & 0.0169 \\
\hline Age $\geq 80$ years & 1.61 & $0.92-2.83$ & 0.0972 & 1.68 & $0.94-3.00$ & 0.0793 & & & \\
\hline ACTS score at baseline & 0.79 & $0.75-0.83$ & $<0.0001$ & 0.79 & $0.75-0.83$ & $<0.0001$ & 0.79 & $0.75-0.82$ & $<0.000$ I \\
\hline History of stroke ${ }^{a}$ & 1.42 & $0.82-2.44$ & 0.2097 & 1.65 & $0.93-2.91$ & 0.0878 & 1.62 & $0.92-2.86$ & 0.0949 \\
\hline History of bleeding & & & & 1.09 & $0.55-2.15$ & 0.8007 & & & \\
\hline Hypertension & & & & 1.01 & $0.62-1.64$ & 0.9797 & & & \\
\hline Diabetes & & & & 1.21 & $0.76-1.91$ & 0.4234 & & & \\
\hline Heart failure & & & & 0.95 & $0.62-1.46$ & 0.8023 & & & \\
\hline Myocardial infarction ${ }^{\mathrm{b}}$ & & & & 0.91 & $0.54-1.54$ & 0.7268 & & & \\
\hline Use of antiplatelet drugs and/or NSAIDs & & & & 0.60 & $0.35-1.02$ & 0.0592 & 0.60 & $0.36-1.00$ & 0.0499 \\
\hline Labile PT-INR & & & & 1.00 & $0.66-1.52$ & 0.9966 & & & \\
\hline
\end{tabular}

Notes: ancludes stroke, transient ischemic attack, and embolism. 'Includes myocardial infarction, peripheral arterial disease, and plaque. Model I was adjusted for gender, age, ACTS score at baseline, history of bleeding, and history of stroke (only "robust" factors). Model 2 was adjusted for factors in Model I+ complicated diseases (hypertension, diabetes, and myocardial infarction), concomitant drugs (antiplatelet drugs and NSAIDs), and INR control status. Model 3 (base model) was adjusted for age and factors with $P<0.2$ in Model I or Model 2.

Abbreviations: ACTS, Anti-Clot Treatment Scale; Cl, confidence interval; NSAID, nonsteroidal anti-inflammatory drug; OR, odds ratio; PT, prothrombin time; INR, international normalized ratio.

identified factors associated with improvement of ACTS burden and benefit scores using a multiple logistic regression analysis.

Patient satisfaction with pharmacological therapy is very important in clinical practice. Satisfaction with and preference for a given pharmaceutical regimen may have a significant impact on medication adherence, ${ }^{13,14,17}$ and higher satisfaction is associated with better anticoagulation control. ${ }^{19}$ Therefore, patient satisfaction with anticoagulant therapy should be considered an important component of maintaining optimal medication adherence.

The results of the current study show that ACTS scores improved after switching from warfarin to apixaban. This finding may stem from patients' relief from the restrictions and requirements associated with warfarin therapy, which are not needed with DOAC treatment. For patients taking warfarin, anticoagulation status should be routinely monitored with PT-INR measurements; such monitoring is not performed for patients taking DOACs. In addition, patients on warfarin must adhere to dietary restrictions and avoid medications that interact with warfarin. These constraints may impose a substantial burden on patients with NVAF who are taking warfarin. Furthermore, restriction on food and drink (including alcohol) is an area in which patients are most dissatisfied with warfarin therapy. Because DOACs are not subject to the same dietary and drug interactions as warfarin, switching to apixaban largely improved the dissatisfaction associated with food and drink restrictions in our survey. When considering individual questions, scores for two treatment burden-related questions - No 6 and No 8 both improved after the switch. Taken together, the increased number of daily doses (once daily to BID) could not have had a large impact on patients' burdens. These results suggest that physicians should give special consideration to patients' dietary preferences before starting anticoagulant therapy and understand the potential frustrations with warfarin-related restrictions. Bleeding tendency during warfarin treatment has been suggested to have an impact on patient satisfaction; therefore, switching from warfarin to apixaban, an anticoagulant that is associated with relatively fewer bleeding events, could decrease patient burden. Surprisingly, history of bleeding and concerns about future bleeding were not significantly associated with improvement of patient satisfaction in the current study. The reasons for this finding are uncertain; however, the results might be explained, at least in part, by the suboptimal INR control during warfarin treatment in Japan. It is well known that concerns of bleeding often lead physicians, particularly non-cardiologists or nonneurologists responsible for primary prevention of stroke, to frequently use low doses of warfarin to control INR values below or around the lower limit of the recommended therapeutic range. This may account for the lower incidence of bleeding and less concerns about a possibility of bleeding. Further investigations, particularly stratified by experience of bleeding events or by INR control status, are needed to validate these results.

Although ACTS burden scores improved, there were no significant changes in ACTS benefit scores after switching 
to apixaban. Relatively high baseline score may not have allowed sufficient room for improvement. In the SAFARI study, researchers investigated patient satisfaction with rivaroxaban treatment for stroke prevention in AF patients and found that the ACTS benefit score significantly increased by $0.4 \pm 2.9$ points $(P<0.001)$, which might have been too marginal to be considered clinically relevant. ${ }^{20}$

A multiple logistic regression analysis revealed ACTS burden score at baseline as one of the factors significantly associated with improvement of ACTS burden scores following treatment, suggesting that lower level of satisfaction with anticoagulant therapy at baseline was associated with a higher likelihood to be satisfied with a new anticoagulant after switching. Physicians should, therefore, communicate effectively with patients to assess the levels of satisfaction with anticoagulant therapy, and, if inadequate, consider switching to a new medication.

Patients aged $>70$ years were more likely to show improved ACTS burden scores after switching to apixaban. The reason for this finding is unclear. It is possible that warfarin-related food restrictions are more of a burden for elderly patients who may prefer traditional Japanese foods, such as fermented soybeans and vegetables that contain vitamin $\mathrm{K}$, and are therefore limited in the diets of patients on warfarin. Similarly, a previous study reported that $58 \%$ of patients, particularly males and patients aged $>70$ years, were interested in switching from warfarin to a DOAC. ${ }^{15}$

In addition to these two factors, we also found that the use of NSAIDs/antiplatelet drugs was a negative independent factor for improved patient satisfaction according to the ACTS burden score. For patients on warfarin, concomitant use of these medications may not only increase the incidence of bleeding but may also heighten patients' apprehension of a bleeding event. Patients' daily lives may be more limited when using these drugs together. Therefore, patients on warfarin may worry about bleeding events and may only find relief from regular monitoring of PT-INR. In one study comparing apixaban and warfarin, apixaban reduced bleeding risk regardless of concomitant antiplatelet medications. ${ }^{21}$ Taken together, these results indicate that apixaban may reduce the burden associated with bleeding.

The high price of DOACs compared to the much lower price of warfarin is one of the major barriers to switching therapies, ${ }^{16}$ and, moreover, patient satisfaction may worsen in response to increased drug costs. However, in our study, self-pay ratio was unrelated to patient satisfaction, despite the higher cost of apixaban. In Japan, the national health insurance system covers all citizens at a standard level, and the self-pay portion of total medical costs, including drug costs, is only $0 \%-30 \%$. This may be a major reason why increased drug costs due to the switch did not have a large impact on changes in patient satisfaction.

Our results illustrate the roles that patient satisfaction, opinion, and preference play in the process of selecting or changing anticoagulant therapy in patients with AF. Sustained improvements in patient satisfaction may be a crucial factor for maintaining adherence to anticoagulant medications.

\section{Limitations}

There were some limitations to this study. First, as an observational study, only patients who had already been scheduled to switch from warfarin to apixaban were enrolled. Therefore, it is likely that patients who were fully satisfied with warfarin may not have been included, which, in turn, may have significantly impacted our results. Second, changes in patient satisfaction were investigated at a single time point (12 weeks after switching to apixaban), and long-term changes were not captured in this study; longer-term assessment is necessary for a more comprehensive analysis of patient satisfaction with apixaban. Third, major cardiovascular risk factors such as oxidative stress, diabetes mellitus, smoking, hypertension, obesity, and heart failure could be associated with the development and progression of AF, and patients included in the current study may have been receiving treatment for these pathological conditions. ${ }^{22}$ More importantly, such treatments might also have an influence on patient satisfaction but were not considered in the current analysis.

\section{Conclusion}

Switching from warfarin to apixaban reduced patientreported treatment burden and thereby improved patient satisfaction with anticoagulant therapy in Japanese patients with NVAF.

\section{Acknowledgments}

The authors thank the doctors who participated in this study (see Table S7 for details). We would like to acknowledge the contribution of Mebix, Inc. to this study including site selection, site monitoring, study management, and data management, and DOT WORLD Co., Ltd. for developing the EDC. We sincerely appreciate MediStatLab Co., Ltd. for its contributions to statistical analysis. We thank Ms. Pearl Gomes from Cactus Communications K.K. for editing the manuscript. This study and editing of the manuscript were supported by Bristol-Myers Squibb K.K and Pfizer Japan Inc. 


\section{Author contributions}

YK, TI, KK, TH, and MY were involved in designing the study, interpreting the obtained results, and critically reviewing the drafted manuscript. MK was involved in designing the study, managing the project, interpreting the obtained results, and critically reviewing the drafted manuscript. MC and MI were involved in designing the study, preparing a statistical analysis plan, managing the project, interpreting the obtained results, and drafting the manuscript. All authors contributed toward data analysis, drafting and revising the paper and agree to be accountable for all aspects of the work.

\section{Disclosure}

YK received honoraria and consulting fees (for speaker, writer, and/or adviser) from Bayer Yakuhin Ltd., BristolMyers Squibb K.K., Daiichi Sankyo K.K., Nippon Boehringer Ingelheim, and Pfizer Japan Inc., and research grants from Daiichi Sankyo K.K. and Nippon Boehringer Ingelheim. TI received research grants from Bristol-Myers Squibb K.K., Daiichi Sankyo K.K., and Nippon Boehringer Ingelheim, and honoraria and consulting fees from Bayer Yakuhin Ltd., Bristol-Myers Squibb K.K., Daiichi Sankyo K.K., Nippon Boehringer Ingelheim, and Pfizer Japan Inc. KK received research grants from Bayer Yakuhin Ltd., Daiichi Sankyo K.K., and Nippon Boehringer Ingelheim, and honoraria and consulting fees from Bayer Yakuhin Ltd., Daiichi Sankyo K.K., Nippon Boehringer Ingelheim, and Pfizer Japan Inc. TH received honoraria and consulting fees from Bayer Yakuhin Ltd., Bristol-Myers Squibb K.K., Daiichi Sankyo K.K., Nippon Boehringer Ingelheim, and Pfizer Japan Inc. MY received a research grant from Nippon Boehringer Ingelheim and honoraria and consulting fees from Bayer Yakuhin Ltd., Bristol-Myers Squibb K.K., Daiichi Sankyo K.K., Nippon Boehringer Ingelheim, and Pfizer Japan Inc. MK is an employee of Bristol-Myers Squibb K.K. MC and MI are employees of Pfizer Japan Inc. The authors report no other conflicts of interest in this work.

\section{References}

1. Benjamin EJ, Levy D, Vaziri SM, D’Agostino RB, Belanger AJ, Wolf PA. Independent risk factors for atrial fibrillation in a populationbased cohort. The Framingham Heart Study. JAMA. 1994;271(11): 840-844.

2. Kokubo Y, Watanabe M, Higashiyama A, Nakao YM, Kusano K, Miyamoto Y. Development of a basic risk score for incident atrial fibrillation in a Japanese general population - the Suita Study. Circ J. 2017;81(11):1580-1588.

3. Wang TJ, Parise H, Levy D, et al. Obesity and the risk of new-onset atrial fibrillation. JAMA. 2004;292(20):2471-2477.
4. Morin DP, Bernard ML, Madias C, Rogers PA, Thihalolipavan S, Estes NA 3rd. The state of the art: atrial fibrillation epidemiology, prevention, and treatment. Mayo Clin Proc. 2016;91(12):1778-1810.

5. Colilla S, Crow A, Petkun W, Singer DE, Simon T, Liu X. Estimates of current and future incidence and prevalence of atrial fibrillation in the U.S. adult population. Am J Cardiol. 2013;112(8):1142-1147.

6. Go AS, Hylek EM, Phillips KA, et al. Prevalence of diagnosed atrial fibrillation in adults: national implications for rhythm management and stroke prevention: the AnTicoagulation and Risk Factors in Atrial Fibrillation (ATRIA) Study. JAMA. 2001;285(18):2370-2375.

7. Dantas GC, Thompson BV, Manson JA, Tracy CS, Upshur RE. Patients' perspectives on taking warfarin: qualitative study in family practice. BMC Fam Pract. 2004;5:15.

8. Siltari A, Vapaatalo H. Vascular calcification, vitamin K and warfarin therapy - possible or plausible connection? Basic Clin Pharmacol Toxicol. Epub 2017 Jun 21.

9. Mozos I, Stoian D, Luca CT. Crosstalk between vitamins A, B12, D, K, C, and E status and arterial stiffness. Dis Markers. 2017;2017:8784971.

10. Yamamoto K, Koretsune Y, Akasaka T, et al. Effects of vitamin K antagonist on aortic valve degeneration in non-valvular atrial fibrillation patients: prospective 4-year observational study. Thromb Res. 2017;160:69-75.

11. Granger CB, Alexander JH, McMurray JJ, et al. Apixaban versus warfarin in patients with atrial fibrillation. $N$ Engl J Med. 2011; 365(11):981-992.

12. January CT, Wann LS, Alpert JS, et al. 2014 AHA/ACC/HRS guideline for the management of patients with atrial fibrillation: a report of the American College of Cardiology/American Heart Association Task Force on Practice Guidelines and the Heart Rhythm Society. Circulation. 2014;130(23):2071-2104.

13. Barbosa CD, Balp MM, Kulich K, Germain N, Rofail D. A literature review to explore the link between treatment satisfaction and adherence, compliance, and persistence. Patient Prefer Adherence. 2012; 6:39-48.

14. Laba TL, Essue B, Kimman M, Jan S. Understanding patient preferences in medication nonadherence: a review of stated preference data. Patient. 2015;8(5):385-395.

15. Attaya S, Bornstein T, Ronquillo N, et al. Study of warfarin patients investigating attitudes toward therapy change (SWITCH Survey). Am J Therap. 2012;19(6):432-435.

16. Elewa HF, DeRemer CE, Keller K, Gujral J, Joshua TV. Patients satisfaction with warfarin and willingness to switch to dabigatran: a patient survey. J Thromb Thrombolysis. 2014;38(1):115-120.

17. Osterberg L, Blaschke T. Adherence to medication. $N$ Engl J Med. 2005;353(5):487-497.

18. Cano SJ, Lamping DL, Bamber L, Smith S. The Anti-Clot Treatment Scale (ACTS) in clinical trials: cross-cultural validation in venous thromboembolism patients. Health Qual Life Outcomes. 2012;10:120.

19. Wang Y, Kong MC, Lee LH, Ng HJ, Ko Y. Knowledge, satisfaction, and concerns regarding warfarin therapy and their association with warfarin adherence and anticoagulation control. Thromb Res. 2014; 133(4):550-554

20. Hanon O, Chaussade E, Gueranger P, Gruson E, Bonan S, Gay A. Patient-reported treatment satisfaction with rivaroxaban for stroke prevention in atrial fibrillation. A French observational study, the SAFARI Study. PLoS One. 2016;11(12):e0166218.

21. Alexander JH, Lopes RD, Thomas L, et al. Apixaban vs. warfarin with concomitant aspirin in patients with atrial fibrillation: insights from the ARISTOTLE trial. Eur Heart J. 2014;35(4):224-232.

22. Gasparova I, Kubatka P, Opatrilova R, et al. Perspectives and challenges of antioxidant therapy for atrial fibrillation. Naunyn Schmiedebergs Arch Pharmacol. 2017;390(1):1-14. 


\section{Publish your work in this journal}

Patient Preference and Adherence is an international, peer-reviewed, open access journal that focuses on the growing importance of patient preference and adherence throughout the therapeutic continuum. Patient satisfaction, acceptability, quality of life, compliance, persistence and their role in developing new therapeutic modalities and compounds to optimize

clinical outcomes for existing disease states are major areas of interest for the journal. This journal has been accepted for indexing on PubMed Central. The manuscript management system is completely online and includes a very quick and fair peer-review system, which is all easy to use. Visit http://www. dovepress.com/testimonials.php to read real quotes from published authors.

Submit your manuscript here: http://www.dovepress.com/patient-preference-and-adherence-journal 